Discussion Paper No. 12-033

The Impact of Burden Sharing Rules on the Voluntary Provision of Public Goods

Martin Kesternich, Andreas Lange, and Bodo Sturm

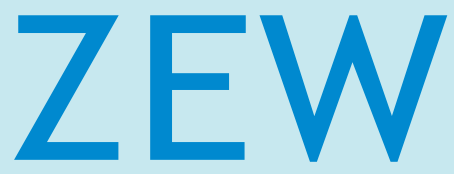

Zentrum für Europäische Wirtschaftsforschung $\mathrm{GmbH}$

Centre for European

Economic Research 
Discussion Paper No. 12-033

\title{
The Impact of Burden Sharing Rules on the Voluntary Provision of Public Goods
}

\author{
Martin Kesternich, Andreas Lange, \\ and Bodo Sturm
}

Download this ZEW Discussion Paper from our ftp server:

http://ftp.zew.de/pub/zew-docs/dp/dp12033.pdf

Die Discussion Papers dienen einer möglichst schnellen Verbreitung von neueren Forschungsarbeiten des ZEW. Die Beiträge liegen in alleiniger Verantwortung der Autoren und stellen nicht notwendigerweise die Meinung des ZEW dar.

Discussion Papers are intended to make results of ZEW research promptly available to other economists in order to encourage discussion and suggestions for revisions. The authors are solely responsible for the contents which do not necessarily represent the opinion of the ZEW. 


\section{Das Wichtigste in Kürze}

Bei der privaten Bereitstellung öffentlicher Güter entscheiden Individuen über ihren freiwilligen Beitrag zu einem gemeinsamen Projekt oder - analog - sie einigen sich auf ein gemeinsames Bereitstellungsniveau in Verbindung mit einer Regel zur Lastenverteilung. Diese Entscheidungsfindung ist besonders dann schwierig, wenn die Akteure neben Freifahreranreizen über unterschiedliche Interessen aufgrund heterogener individueller Präferenzen verfügen. Ein wichtiges Beispiel für dieses Problem ist die Debatte über eine gerechte Lastenverteilung bei der Emissionsreduktion in der internationalen Klimapolitik.

Das Ziel dieses Papiers ist es, experimentell zu untersuchen, inwieweit unterschiedliche Regeln zur Lastenverteilung das gemeinsame, von jedem Akteur akzeptierte, Bereitstellungsniveau eines öffentlichen Guts beeinflussen. Dabei fokussiert sich die Fragestellung auf regelbasierte Beitragsmechanismen, welche sich aus dem Prinzip des kleinsten gemeinsamen Nenners ableiten lassen: Das Minimum aller Vorschläge über einen individuellen Beitrag zum gemeinsamen Projekt bildet dabei eine untere Grenze für die anschließende Beitragsentscheidung. Dieses Prinzip spiegelt sich in vielen internationalen Verhandlungen wider: Alle Teilnehmer müssen eine entsprechende Vereinbarungen unterschreiben und ratifizieren, bevor diese in Kraft tritt und bindend für sie ist. Dabei ist der Vorschlag mit dem kleinsten gemeinsamen Nenner oftmals ausschlaggebend.

In einem Laborexperiment werden verschiedene Minimum-Beitragsregeln auf Basis des Prinzips des kleinsten gemeinsamen Nenners in einem Öffentlichen-Gut-Spiel getestet und verglichen. Die Agenten unterscheiden sich in ihrem Nutzen aus dem gemeinsamen Projekt. Die experimentelle Anordnung ermöglicht dabei einen Vergleich von Regeln, die die Koordination der gesamten Gruppe verlangen, mit Mechanismen, welche eine Koordination unter jeweils gleichen Spielern vorsehen.

Die Ergebnisse zeigen, dass sämtliche Minimum-Beitragsregeln den Gewinn der Spieler gegenüber der Standardanordnung, in der das öffentliche Gut ohne zusätzliche Regeln nur durch freiwillige Beiträge aller Spieler bereitgestellt wird, signifikant erhöhen. Hervorzuheben ist dabei, dass im Vergleich zu allen anderen untersuchten Mechanismen eine Regel, welche die Gewinne der heterogenen Spieler durch unterschiedliche Beitragsforderungen ausgleicht, zumindest einige Akteure besser und niemand schlechter stellt. Dieses empirische Resultat lässt vermuten, dass eine entsprechende Regel zur Lastenaufteilung in der Bereitstellung öffentlicher Güter, welche alle Spieler miteinbezieht und explizite Umverteilungsmechanismen berücksichtigt, erhebliche Kooperationsgewinne realisieren kann. Diese Erkenntnisse tragen damit zur Erforschung effizienter institutioneller Rahmenbedingungen für die private Bereitstellung öffentlicher Güter bei und liefern gleichzeitig einen Beitrag zur derzeitigen Diskussion in der internationalen Klimapolitik über alternative Möglichkeiten zur Ausgestaltung eines Kyoto Nachfolgeabkommens. 


\section{Non-technical Summary}

The provision of public goods often faces the problem that agents need to voluntarily decide on their own contributions or - alternatively - have to agree upon some desired provision level of the public good in combination with a specific burden sharing rule. This challenge is particularly demanding, when, in addition to enforcement problems, interests differ among players due to heterogeneous preferences. International climate policy is an important example. While strong free-riding incentives prevent a pure voluntary and uncoordinated solution, international negotiations are loaded with debates on equity issues, i.e. on what constitutes a fair distribution of a global reduction target for greenhouse gas emissions.

In this paper, we investigate how burden sharing rules may impact the provision level of a public good that all agents voluntarily accept. We focus on different rule-based contribution mechanisms that are based on the principle of the smallest common denominator: all agents can suggest a minimum provision level of the public good that is allocated across agents according to some predetermined rule. The minimum of all proposals, i.e. the lowest common denominator, then takes effect and creates a "lower bound" for the individual contribution levels. This approach reflects many real world institutional arrangements that either involve a simultaneous choice of provision goal and burden sharing, or sequentially try to first determine the burden sharing rule before then deciding upon the provision goal. Since each participating country needs to sign and ratify the agreement, the player with the smallest proposal is pivotal. Countries can, however, voluntarily go beyond their obligations.

We experimentally compare the ability of different rule-based contribution schemes to overcome the inefficiency in public good provision. Players differ with respect to their benefits from the public good, each group consists of two low-type and two high-type agents. Our results indicate that all rule-based contribution schemes significantly increase both payoff levels relative to the standard voluntary contribution mechanism. Interestingly, the equalpayoff rule Pareto-dominates all other rules. This finding is particularly surprising since all rules are predicted to generate coordination on efficient, but differing allocations. Explicitly addressing redistribution among heterogeneous players by equalizing payoffs performs best due to substantially higher contributions from high-type players. This holds in particular relative to the scheme where high- and low-type players separately can determine their minimum contribution: here, low-type agents end up contributing at the same rate as in the equal-payoff treatment while high-type agents fail to efficiently coordinate.

Our results lend insights not only into efficient institutional design for voluntary private provision of public goods, but may also inform the recent climate policy debate on whether to have small agreements among more homogeneous players instead of having one comprehensive Kyoto style agreement that creates complicated burden sharing issues. 


\title{
The Impact of Burden Sharing Rules on the Voluntary Provision of Public Goods
}

\author{
Martin Kesternich ${ }^{1}$, Andreas Lange ${ }^{1,2}$ and Bodo Sturm ${ }^{1,3}$ \\ ${ }^{1}$ Centre for European Economic Research (ZEW), kesternich@zew.de \\ ${ }^{2}$ University of Hamburg, andreas.lange@wiso.uni-hamburg.de \\ ${ }^{3}$ Leipzig University of Applied Sciences, bodo.sturm@wiwi.htwk-leipzig.de
}

Version: April 30, 2012

\begin{abstract}
We investigate how burden sharing rules may impact the voluntary provision of a public good which generates heterogeneous benefits to agents. We compare different rule-based contribution schemes that are based on the principle of the smallest common denominator: all agents can suggest a minimum provision level of the public good that is allocated across agents according to some predetermined rule. We find that rule-based contribution schemes significantly increase payoff levels relative to the VCM. Important differences exist between the rules. Contrary to theory predictions, the equal-payoff rule Pareto-dominates all other rules. This also holds relative to a scheme where different types of players separately can determine their minimum contribution levels. Our results lend insights into the efficient institutional design for voluntary private provision of public goods, and how burden sharing rules interact with efficiency when agents are heterogeneous.
\end{abstract}

Keywords: public goods, institutions, minimum contribution rules, cooperation, heterogeneity

JEL: C72, C92, H41

Acknowledgement: Financial support by the German Federal Ministry of Education and Research (FKZ 01UN1016A) is gratefully acknowledged.

Correspondence: Andreas Lange, University of Hamburg, Von Melle Park 5, 20146 Hamburg, Germany, email: andreas.lange@wiso.uni-hamburg.de. 


\section{Introduction}

The provision of public goods often faces the problem that agents need to voluntarily decide on their own contributions or - alternatively - have to agree upon some desired provision level of the public good in combination with a specific burden sharing rule. This challenge is particularly demanding, when, in addition to enforcement problems, interests differ among players due to heterogeneous preferences. International climate policy is an important example. While strong free-riding incentives prevent a pure voluntary and uncoordinated solution, international negotiations are loaded with debates on equity issues, i.e. on what constitutes a fair distribution of a global reduction target for greenhouse gas emissions (e.g., Nordhaus 2010).

In this paper, we investigate how burden sharing rules may impact the provision level of a public good that all agents voluntarily accept. We focus on different rule-based contribution mechanisms that are based on the principle of the smallest common denominator: all agents can suggest a minimum provision level of the public good that is allocated across agents according to some predetermined rule. The minimum of all proposals, i.e. the lowest common denominator, then takes effect and creates a "lower bound" for the individual contribution levels.

This approach reflects many real world institutional arrangements that involve either a simultaneous or a sequential choice of provision goal and burden sharing rule. For the climate policy example, a pre-negotiated rule, e.g. using uniform obligations among countries (Barrett 2003), may particularly be beneficial in reducing negotiation costs when the total target changes over time. Since each participating country needs to sign and ratify the agreement, the player with the smallest proposal is pivotal. Countries can, however, voluntarily go beyond their obligations. Similar burden sharing rules can apply to individual decisions on voluntary public good provision. In the literature, the interaction of burden sharing has been discussed within the concept of Lindahl prices (Silvestre 1984, Sato 1987), where the outcome is given when no agent would desire reducing the public-good provision simultaneously with his own individual contribution to the public good (see van den Nouweland et al. 2002, Bilodeau and Gravel 2004). We contribute to the literature by experimentally comparing the ability of different rule-based contribution schemes to overcome the inefficiency in public good provision. 
Our paper relates to the vibrant literature on the voluntary provision of public goods. Orzen (2008) and Dannenberg et al. (2010) have already shown the benefits from such a least common denominator rule when agents are homogeneous. It may not be surprising that these authors find that often this mechanism allows groups to reach large provision levels, thereby generating substantial welfare gains relative to the voluntary contribution mechanism, as players have a weakly dominant strategy to suggest an efficient provision and the only fair burden sharing rule allocates the same burden to all players. However, cooperation in many settings faces the challenge of substantially differing interests, for example due to different wealth or costs and benefits from the public good. Our paper explores the performance of rule-based contribution schemes for heterogeneous agents. We thereby focus on differences in the agents' benefits from the public good.

There is a significant literature on voluntary public good provision when players are heterogeneous. Many papers concentrate on endowment heterogeneity. Ledyard (1995) and Zelmer (2003) each review several experimental studies and find a negative impact of endowment heterogeneity on contributions. ${ }^{1}$ Spraggon and Oxoby (2009) show endowment effects to be sensitive to the endowments' origin. In our experiment, we keep the endowment identical across agents, and rather concentrate on heterogeneous public good benefits.

In their literature reviews, both Ledyard (1995) and Zelmer (2003) expose higher marginal per capita returns (MPCR) to enhance cooperation in public goods experiments. However, this effect does not necessarily remain robust if group members differ in their MPCRs. Fisher et al. (1995), for example, report only small tendencies low-type players (MPCR $=0.3$ ) contributing more and high-type players $(\mathrm{MPCR}=0.7$ ) contributing less in heterogeneous settings in contrast to homogeneous groups. Tan (2008) shows that heterogeneity with respect to contributing costs lowers cooperation. Reuben and Riedl (2009) find that heterogeneity in endowments or benefits do not alter decision behavior if no punishment options exist. With punishment they investigate contribution norms based on different fairness principles. For instance, with unequal endowments or heterogeneous benefits, contributions are proportional to endowments or respectively to the ratio of marginal benefits. Fellner et al. (2011) investigate the impact of productivity isolated from the costs of contribution. They report that information about heterogeneity increases cooperation but alters contribution norms. While

\footnotetext{
${ }^{1}$ Van Dijk et al. (2002) and Cherry et al. (2005) as well as Anderson et al. (2008) also confirm the negative endowment effect. In contrast, Chan et al. $(1996,1999)$ and Buckley and Croson (2006) show potential positive effects. Recent studies on this topic include Sadrieh and Verbon (2006), Koukoumelis et al. (2010) and Georgantzis and Proestakis (2011).
} 
less information leads to more equal contributions, in case of full information subjects focus on group efficiency. Considering an endogenous coalition formation to provide public goods, McGinty et al. (forthcoming) focus on different distribution rules for coalition payoffs among heterogeneous players and find that efficiency substantially depends on the rule for division of coalitions’ benefits.

In this paper, we experimentally test and compare several rule-based contribution schemes that are based on the lowest common denominator rule. We consider a linear repeated fourperson public good game with players that differ in their benefits from the joint project. Each group consists of two high-type players $(\mathrm{MPCR}=0.7)$ and two low-type players $($ MPCR $=0.3)$. We compare the traditional VCM with four other treatments that differ in the implemented burden sharing rule: (i) two variants of equal minimum contribution requirements for all players, (ii) separated minimum levels for low- and high-type players, and (iii) a burden sharing rule aiming at equalizing payoffs of all players. The first rule thereby equally distributes the contribution obligation on all players and thereby extends the smallest common denominator rule (Orzen 2008, Dannenberg et al. 2010) to a heterogeneous player setting. The second rule allows both types of players to separately implement minimum contribution requirements that are only binding for players of their own type. This treatment is inspired by proposals in international climate policy negotiations to have small agreements among more homogeneous players rather than creating the problem of complicated discussion on burden sharing rules when all countries try to agree on a comprehensive treaty as in the Kyoto process (Olmstead and Stavins 2006). The third rule exogenously determines a differentiated burden regime that is inspired by calls for reducing payoff inequalities.

Our results indicate that all rule-based contribution schemes significantly increase both payoff levels relative to the VCM. Interestingly, the equal-payoff rule Pareto-dominates all other rules. This finding is particularly surprising since all rules are predicted to generate efficient, but differing allocations. Explicitly addressing redistribution among heterogeneous players by equalizing payoffs performs best due to substantially higher contributions from high-type players. This holds in particular relative to the scheme where high- and low-type players separately can determine their minimum contribution: here, low-type agents end up contributing at the same rate as in the equal-payoff treatment while high-type agents fail to reach similar contribution levels. This result thereby indicates an important caveat of the smallest common denominator rule: differently from Orzen (2008) and Dannenberg et al. (2010), even homogeneous agents may fail to achieve efficient outcomes in presence of players with other characteristics. We therefore find a superiority of appropriately designed 
rule-based contribution schemes that involve all players rather than having separate schemes for players of the same type.

The remainder of the paper is organized as follows. Section 2 provides a short theoretical framework in order to derive the predictions for our experiment. The experimental design is described in section 3. We discuss our results in section 4, before concluding in section 5 .

\section{Theoretical Predictions}

In our experiment, we consider different institutions by which agents may decide upon the provision of a public good. They include a standard voluntary provision mechanism (VCM) as well as different rule-based contribution schemes. In these, players first are either requested to suggest a desired total provision level, whose costs are then allocated across the agents according to differing burden sharing rules or subjects make suggestions for individual minimum contributions from which a lower bound on contribution is derived.

The payoff structure in all treatments is given by a linear public good game. That is, the payoff to player $i$ is given by

$$
\pi_{i}=e-q_{i}+b_{i} Q
$$

where $e$ denotes the initial endowment, $q_{i}$ the individual contribution, $b_{i}$ the marginal benefit from the public good to player $i$, and $Q=\sum_{j=1}^{n} q_{j}$ the total provision level of the public good. Players differ with respect to their marginal benefits from the public good only. As standard, we assume that $b_{i}<1$ and $\sum_{j=1}^{n} b_{j}>1$. In our experiment, we consider groups of four players $(n=4)$ that consist of two low-type players $\left(b_{\text {low }}=0.3\right)$ and two high-type players $\left(b_{\text {high }}=0.7\right)$. The endowment is given by $e=20$ such that $q_{i} \in[0,20]$.

\section{Voluntary contribution mechanism (VCM)}

In the traditional VCM, individuals simultaneously choose their contribution level $q_{i}$. Since $b_{i}<1$ for all agents, individual utility maximization yields the Nash equilibrium of zero contributions to the public good both for low- and high-type players with individual earnings $\pi_{i}=e$. 


\section{Common individual minimum contribution mechanism (min-I-q)}

We next consider a setting in which all subjects first simultaneously suggest a common individual minimum contribution level. After these minimum proposals $q_{i}^{\text {min }}$ are received from all agents, this rule requires all four players to provide at least the smallest suggested level, i.e. $q_{i} \geq q^{\min }=\min _{j} q_{j}^{\min }$. Under these conditions, each agent has a weakly dominant strategy to suggest $q_{i}^{\min }=e$ : in the second stage, no payoff maximizing player would contribute more than required $\left(q_{i}=q^{\min }\right)$. When making their minimum proposal $q_{i}^{\min }$ in the first stage, agents therefore need to recognize their potential impact on the provision levels of all other players such by suggesting a higher minimum they can only increase their own payoff $\left(\pi_{i}=e-q^{\min }+b_{i} n q^{\min }\right)$ since $n b_{i}>1$. We therefore predict $q_{i}^{\text {min }}=e$ such that an efficient outcome results $\left(\pi_{i}=b_{i} n e\right)$.

\section{Separate individual minimum contribution mechanism (min-II-q)}

In the next treatment, we consider a modification to min-I-q in which the high- and low-type players may suggest an individual minimum contribution level that applies only to their own type. This treatment incorporates the idea that a forced equal contribution obligation that is implicitly present in min-I-q may not be acceptable when agents are heterogeneous. Rather, differentiated obligations for the respective player types are possible. That is, low-type players agree on their own binding minimum level $q_{l o w}^{\min }$ and high-type players choose $q_{\text {high }}^{\min }$. Again, the smallest suggested level is binding for the respective type. Theory predicts full contribution if $1<\left(\frac{n}{2}\right) b_{i}$ which holds only for the high-type players. Low-type players have a dominant strategy of suggesting $q_{i}^{\min }=0$. The payoffs are therefore predicted as $\pi_{i, h i g h}=$ $b_{\text {high }}\left(\frac{n}{2}\right) e$ and $\pi_{i, l o w}=e\left(1+\left(\frac{n}{2}\right) b_{\text {low }}\right)$. Note that this allocation is efficient: since we assumed that no direct transfers are possible, no other allocation exists that treats agents of the same type identically and generates a larger payoff to all players.

The two treatments min-I- $q$ and min-II- $q$ rely on a minimum mechanism in which players can suggest an individual contribution level. We next consider contributions schemes in which all players suggest a total provision level $Q$ that is distributed across agents to a specific rule such 
that $q_{i} \geq \alpha_{i} Q$ where $\sum_{i} \alpha_{i}=1 .^{2}$ We define such schemes as follows: In a first step, each agent can suggest a total provision level $Q_{i}$. The minimum of the suggested levels is then decisive for contributions in the second stage: $Q^{\min }=\min _{j} Q_{j}$ such that $q_{i} \geq \alpha_{i} Q^{\min }$. In the second stage, players again have no incentive to contribute more than required, i.e. $q_{i}=$ $\alpha_{i} Q^{\mathrm{min}}$. The payoff is therefore given by $\pi_{i}=e-\alpha_{i} Q^{\min }+b_{i} Q^{\min }$ such that agents have a weakly dominant strategy to suggest the maximal possible $Q_{i}$ if $\alpha_{i} \leq b_{i}$, while suggesting $Q_{i}=0$ is dominant if $\alpha_{i}>b_{i}$.

The strategic features of min- $I-q$ coincide with a setting in which $\alpha_{i}=1 / n$, that is an egalitarian burden sharing rule. The predictions in min-II- $q$ coincide with a setting in which $\alpha_{\text {low }}=0$ and $\alpha_{\text {high }}=\frac{2}{n}=\frac{1}{2}$, that is a rule that allocates the burden only to high-type players.

\section{Equal contribution treatment (min-I-Q)}

In our experiment, we introduce a treatment min-I-Q with $\alpha_{i}=1 / n$ in order to control for framing effects. As in $\min -I-q$, the predictions are $Q^{\min }=n e$, with $\pi_{i}=b_{i} n e$.

\section{Equal payoff treatment (min-I-Q-eq)}

We further consider a burden sharing rule that is motivated by reaching equal payoffs. That is, the $\alpha_{i}$ values are determined such that the predicted payoff:

$$
\pi_{i}=e+\left(b_{i}-\alpha_{i}\right) Q
$$

is identical for all players $i$. In general, this implies that

$$
\alpha_{i}=b_{i}-\frac{1}{n}\left(\sum_{j} b_{j}-1\right)
$$

which in our experiment would require $\alpha_{\text {low }}=0.05=0.3-(2-1) / 4$ and $\alpha_{\text {high }}=0.45=$ $0.7-(2-1) / 4$. Note, however, payoff equality can only be reached if $\alpha_{\text {high }} Q^{\text {min }} \leq e$, or $Q^{\text {min }} \leq 20 / 0.45=44.4$. In our experiment, we therefore distribute the burden for $Q^{\text {min }}>$

\footnotetext{
${ }^{2}$ For the sake of allowing the reader to better follow the remainder of the paper, we would like to explain the notation of our treatments: it indicates whether the treatment implements a minimum threshold ("min" in all treatments except VCM), whether the individual contribution requirement is based on one or two separate minimum thresholds ("I" in min-I-q, min-I-Q, min-I-Q-eq, "II" in min-II-q), and whether subjects propose an individual contribution level $\mathrm{q}_{\mathrm{i}}^{\mathrm{min}}$ or a total level $\mathrm{Q}_{\mathrm{i}}^{\min }$ (“q” in min-I-q, min-II-q, “Q” in min-I-Q, min-I-Q-eq).
} 
20/0.45 such that the high-type players contribute all their endowment, while allocating a minimum contribution of $\left(Q^{\min }-40\right) / 2$ to low-type players.

Given the parameters in our experiment, high-type players again have a weakly dominant strategy to suggest a group minimum contribution level of $Q_{\text {high }}^{\min }=80$ which would lead to unequal payoffs for both players. As low-type players only gain as long an increase in $Q^{\text {min }}$ also lead to increased burden to high-type players, i.e. as long as $Q^{\min } \leq 20 / 0.45=44.4$, they are predicted to suggest $Q_{\text {low }}^{\min }=44$.

Our predictions are summarized in Table 1. Figure 3 illustrates the predicted payoffs to lowand high-type players under VCM (point A), min-I-Q and min-I- $q$ (Point B), min-II- $q$ (point C), and min-I-Q-eq (Point D), as well as the line of all efficient allocations that give equal payoff to players of same type (line connecting B and C). Note that all rule-based contribution schemes that we consider lead to efficient outcomes (under the assumption that no direct transfers are feasible between agents). That is, no rule is predicted to dominate another. We will test these predictions in our experiment.

\section{Experimental Design}

The experiment was run in November 2011 at the MaXLab laboratory of the University of Magdeburg in Germany. We recruited 336 students from various disciplines. Each student took part in one of 14 sessions with 24 subjects each. ${ }^{3}$ On average, a session lasted about 60 minutes. At the beginning of each session, subjects were seated at separated linked computer terminals. We used z-tree software (Fischbacher 2007) for programming and ORSEE (Greiner 2004) for recruiting. In each session, we randomly created six groups of four players with two high-type and two low-type players. Subjects were not aware of their exact partners. Each player remained the same type in the same group throughout the whole experiment (partner matching). All relevant information on players' type (high-type player or low-type player), contributions (tokens) and payoffs (in Labdollars LD) was transmitted via screen. No direct communication between participants was allowed, only the four players of one group received full information on offers, decisions and payoffs within their group on their screens. In a first step, subjects received a set of experimental instructions which included verbal descriptions, numerical examples and control questions to make sure that every participant understood the

3 Due to a typing error in our z-tree program, we had to remove the results of one group of four players in the first session from our analysis. 
game. ${ }^{4}$ In a second step, the experiment was started on the computer. A session consisted of 12 rounds, the first two being practice periods. At the end of each session, one non-practice round was randomly chosen to determine individual earnings for each player. The exchange rate between Euro and LabDollar (LD) was 1:2.5. On average, subjects earned about 11 Euro. No additional show-up fee was paid. The experimental design is summarized in Table 2.

\section{Experimental Results}

Our experimental design enables us, on the one hand, to test our theoretical predictions regarding public good contribution levels under heterogeneity across different mechanisms. On the other hand, we may observe "pattern" of individual behavior and, thus, develop a better understanding which mechanisms perform best when heterogeneous individuals have the option to contribute to a public good. We craft our results both by pooling the data across all ten periods and by reporting the results in the last five periods. We later explore the effects of time on contribution schedules in more detail.

Table 3 provides mean contribution levels for each of our treatments and Figure 1 provides a graphical depiction of the data. Averaged over all periods, contributions are lowest in VCM (5.5 tokens) and highest in the equal-payoff treatment min-I-Q-eq (9.4). These differences are even more pronounced when concentrating on the last five periods (VCM 3.9, min-I-Q-eq 9.9). While a comparison of contributions is indicative of the obtained efficiency, we first focus on the payoff comparisons across treatments. In our discussion, we hereby concentrate on the last five periods. All results are, however, also reported for all ten periods in Table 4.

We first establish the following result on the benefits of rule-based contribution schemes:

\section{Result 1.}

Rule-based contribution schemes lead to larger payoffs than VCM.

Focusing on the last 5 periods, average profit over all players is minimal in VCM (23.91 LD) and reaches its maximum in min-I-Q-eq (29.91 LD). Hereby, average payoffs are significantly larger under all rules than under VCM ( $\mathrm{p}<0.05$ for min-I- $q, \mathrm{p}<0.01$ for all other rules). ${ }^{5}$

\footnotetext{
${ }^{4}$ We provide an example of instructions and screenshots in the Appendix.

${ }^{5}$ In this section, we refer to exact two-sided Mann-Whitney U (MW U) tests with the average contribution by one group or subgroup (high-type or low-type) as the unit of observation.
} 
These benefits accrue in particular to high-type agents $(\mathrm{p}<0.01$ in all treatments relative to $V C M$ ), while low-types benefit particularly in treatments that differentiate the burden ( $\mathrm{p}<0.01$, min-II- $q$, min-I-Q-eq relative to $V C M$ ), while not significantly doing better in treatments that require identical contributions from all players (min-I- $q$ and $\min -I-Q$ ).

These results on payoff comparisons are confirmed by a series of random-effects regression models ${ }^{6}$ (see Table 5). Average profits over all players and periods are significantly higher in all treatments than in VCM except in min-I- $q$ (at least $\mathrm{p}<0.10$ for all other rules) (column 1 ). This average treatment effect is largest for min-I-Q-eq. ${ }^{7}$ The benefits of rule-based provision of public goods relative to VCM particularly occur over time. While we confirm the standard result that average contributions in VCM decline significantly over time, regression results suggest the downward trends to be weaker in all other treatments (column 2). In min-I-Q-eq, average contributions are even increasing over time $(\mathrm{p}<0.05)$. A closer look indicates differences in payoffs between the two types because of higher benefits for high-type players in all treatments $(\mathrm{p}<0.01)$ (column 3). Focusing on the last five periods, these differences are most pronounced in min-I- $q$ and min- $I-Q$ where equal minima for all types are implemented (columns 4 and 5), while tendencies of payoff harmonization exist for rules that explicitly address the differentiation of burdens ( $\min -I I-q$ and min-I-Q-eq). Payoff gains for low-type agents are largest in min-I-Q-eq $(\mathrm{p}<0.01)$. In min-I- $q$, they loose in contrast to VCM $(\mathrm{p}<0.05)$.

For low-type agents, profits in min-I-Q-eq are even increasing over time $(\mathrm{p}<0.01)$. An additional downward trend for high-type agents relative to the trend for low-type players occurs in VCM and min-II-q.

While Result 1 was expected under our theoretical predictions, it nicely adds to findings by Orzen (2008) and Dannenberg et al. (2010) who show the benefits from minimum-rules for homogeneous agents. We show that such minimum-contribution rules may also generate efficiency gains when agents differ significantly in their benefits from the public good. This even holds for rules that require equal contributions from all players. However, our results also indicate important benefits from differentiating the burden across players by accounting for their different benefits from the public good. In particular, we observe that low-type players obtain significantly larger payoffs under rules that do not require them to contribute at

\footnotetext{
${ }^{6}$ This estimation procedure enables us to allow for unobserved subject-specific differences. We use a randomeffects Feasible Generalized Least Square estimator (RE FGLS) for determining differences in individual payoffs.

${ }^{7}$ Throughout the paper, the discussion on differences among estimated regression coefficients is based on underlying Wald Tests.
} 
the same rate as high-type agents: min-II-q (24.45 LD) leads to larger payoffs than min-I- $q$ (21.91 LD) and min-I-Q (22.06 LD); min-I-Q-eq (28.51 LD) leads to larger payoffs than any other rule (all differences significant, $\mathrm{p}<0.01$ ). While these profit gains for low-type agents hurt the high-type agents when comparing min-I-Q (32.10 LD) with min-II-q (29.14 LD) $(\mathrm{p}<0.05)$, also high-type agents benefit from the equal-payoff rule min-I-Q-eq (31.32 LD) ( $\mathrm{p}<0.01$, compared with all rules besides min-I-Q).

We therefore obtain the following result:

\section{Result 2.}

The equal-payoff rule Pareto-dominates all other burden sharing rules, including the VCM.

Table 5 provides further evidence for this result. It should be noted that the benefits from minI-Q-eq relative to other treatments for low-type agents already accrue in the first five periods. The important difference, however, occurs over time as we have stated above. Average profits in all treatments tend to decrease over periods, except for min-I-Q-eq. In this treatment, profits for low-type subjects are increasing in the last 5 periods $(\mathrm{p}<0.01)$. Our regression results suggest that this effect may be smaller for high-type players, but the difference is not significant.

It should be noted, however, that almost no group chooses the efficient provision level that was predicted by the theory. Figure 3 plots average profits for high- and low-type players for each group in the last 5 periods. As stated in the previous section, the points $\mathrm{B}, \mathrm{C}$, and $\mathrm{D}$ denote the equilibrium payoffs that would be predicted under the respective burden sharing rules. Point A corresponds to the zero contributions as predicted for VCM. While significant profit gains relative to VCM predictions are realized, most groups do not come close to the Pareto frontier. For example, many groups in min-I- $q$ and min-I-Q choose to contribute along the line $A B$ towards the Pareto frontier, thereby suggesting that they did not contribute more than was demanded by the minimum rule, but only few groups came close to achieving efficiency. In min-II- $q$, only one group obtains contribution levels along AC, for all other groups low-type players contributed a positive amount and thereby benefited the high-type players more. For the payoff-equality rule in min-I-Q-eq (along AD) average efficiency gains were largest. In this treatment, many groups managed to come close to the efficiency frontier. 
These payoff differences correspond to different contribution levels that can be observed in our random-effects regression models ${ }^{8}$ in Table $6 \mathrm{a}$ and $6 \mathrm{~b}$. Average contributions to the public good across all players and time periods in all treatments are higher than in VCM (at least $\mathrm{p}<0.05$ except for min-I-q), with the effect being strongest in min-I-Q-eq (columns 1 ). These treatment differences are particularly driven by different time trends: Overall, we observe a positive trend for min-I-Q-eq (at least $\mathrm{p}<0.05$ ), but declining average contributions for all other treatments (significant only for VCM at p $<0.01$ in Table 6a (column 2), but for all other treatments in Table 6b (column 2)). The temporal trends can also be identified by looking at the underlying contribution decisions in Figure 1, it is easily seen that mean contributions do not differ across treatments in the first period. Figure 1 indicates that the contributions in all treatments, except min-I-Q-eq, are decreasing over time. The drop in contributions is strongest in VCM. The lower part of Figure 1 shows how both types contribute to these differences. Concentrating on low-type players (column 4 in Table 6a and $6 b)$, we observe that contributions decline over time in VCM and min-II- $q$, but are rather stable in the other treatments. The increases in average contributions relative to VCM in min$I I-q$ and in min-I-Q-eq are thereby largely driven by high-type players (columns 3 and 4). No difference exists between the contributions of low-type players between min-II- $q$ and min- $I$ $Q$-eq, while high-type players give significantly more in min-I-Q-eq. The downward time trend in $\min -I I-q$ is significantly less pronounced for high-type players relative to low-type players, but in aggregate only leads to stable contributions of high-type players over time. In min-I-Q-eq, however, there is no clear statistical evidence for a downward trend for low-type players exists while contributions for high-type subjects are rising in the last 5 periods $(\mathrm{p}<0.01)$. This increase in contributions by high-type players thereby drives the dominance of the equal-payoff rule as observed in Result 2.

We can therefore formulate the following result that complements our previous results:

\footnotetext{
${ }^{8}$ We follow our estimation strategy which we applied for determining differences in individual payoffs and use a random-effects Feasible Generalized Least Square estimator (RE FGLS) for analyzing individual contribution behavior. In addition, for robustness check, we further apply a Tobit estimator (RE Tobit). The latter estimator controls for the fact that the dependent variable (individual contributions to the public good in each period) is both left- and right-censored with a lower limit of 0 (20.12\% of all contribution decisions) and an upper limit of 20 (9.67\% of all contribution decisions). Specification tests suggest that the results of the Tobit estimator are not sensitive to the number of quadrature points used in the estimation process.
} 


\section{Result 3.}

Contributions increase over time in min-I-Q-eq, but show a downward trend in all other treatments, particularly in VCM. For low-type players, there is no downward trend in min-I-q and min-I-Q, such that these treatments lead to higher contributions by low-type players in the last periods than the other treatments. For high-type players, contributions are largest in min-I-Q-eq and even increase over time.

Result 3 already demonstrates different time trends for low- and high-type players: the dominance of min-I-Q-eq appears to be primarily driven by increased contributions by hightype players themselves. They contribute 16.4 tokens on average in the last 5 periods in min- $I$ Q-eq, while their contributions are significantly smaller in all other treatments $(\mathrm{p}<0.01)$. Conversely, low-type agents contribute less in this treatment (3.4 tokens) than under any other non-differentiating rule-based scheme (5.7 in min- $I-q, 6.2$ in min-I-Q, p <0.01). Interestingly, low-type agents' contributions are not significantly different in min-II- $q$ (3.7) than under the equal-payoff treatment. This implies that min-I-Q-eq allows high-type agents to come closer to their efficient contribution level than they do under the min-II- $q$ treatment which also had predicted the two high-type players to contribute their full endowment. Instead, they only achieve an average 9.9 tokens in this treatment.

These lower contribution levels are primarily driven by the lower minimum proposals. In fact, only 3 out of 18 groups of high-type players in min-II- $q$ achieve a binding minimum proposal of at least 18 in period 10. Seven groups of high-type players do not achieve any cooperation, i.e. stay at a zero level in period 10. In contrast, 14 out of 18 groups in min-I-Q-eq achieve a total provision level of the public good that requires high-type players to contribute at least 18 in period 10. Considering only the minimum proposals by high-type players, all 18 groups of two would suggest to take on at least 18 tokens as obligation. In fact, 16 pairs of high-type players in min-I-Q-eq suggest provision levels in period 10 that would require them to contribute all 20 tokens.

We therefore formulate the following result: 


\section{Result 4.}

An appropriately designed burden sharing scheme that involves all players allows high-type players to coordinate over time more effectively than a scheme under which players of the different types separately choose their binding minimum contribution levels.

We consider Result 4 as being rather surprising: it is obvious that low-type agents under the equal-payoff scheme will suggest high provision levels up to $Q^{\min }=44$ which would require almost full contribution of high-type subjects, but relatively little from low-type players (less than 3, see Table 1). Anticipating low-types' payoff maximization behavior, high-type agents' best answer is to suggest a minimum which is equal or higher than $Q^{\text {min }}=$ 44. Effectively, this scheme therefore should have similar effects as the min-II- $q$ treatment where the two high-type players choose their binding contribution level only among themselves. However, we observe significantly less efficient choices in min-II- $q$ which leads to the dominance of the equal-payoff rule.

The missing cooperation among high-type players in min-II- $q$ stands in conflict with findings by Orzen (2008) and Dannenberg et al. (2010) who show that homogenous groups achieve large cooperation levels under the lowest common denominator scheme. Our results therefore suggest that coordination is hampered when other, different-type players, are present.

This difference in the decisions by high-type players in min-II- $q$ and min-I-Q-eq is particularly surprising as the contributions of low-type players do not differ between the two treatments. We can therefore only speculate about the reasons for this dominance of the equalpayoff treatment: on the one hand, min-I-Q-eq may have intuitively appealing properties as it automatically equalizes payoffs. Our results can be rationalized when agents are sufficiently inequality-averse (compare Fehr and Schmidt 1999, Charness and Rabin 2002). On the other hand, efficiency may be improved in min-I-Q-eq since all players' suggested minimum levels for the aggregate provision level are treated identically. Differently in min-II-q, each player type makes proposals that are treated separately. As a result, high-type players may be influenced by explicitly observing small minimum proposals from low-type players, while not recognizing that decoupling from those by coordinating only among themselves is optimal for the two high-type players. 


\section{Conclusions}

Forming institutions to secure the provision of global public goods is a complicated endeavor. In general, the success of a decentralized institution to provide a public good depends on two interlinked challenges: on the one hand, the institutional arrangements need to overcome free rider incentives. On the other hand, as soon as subjects are heterogeneous, any given institution has to cope with equity issues or equivalently the burden sharing of the total costs. In this paper, we tested different institutions with respect to their ability to succeed along these two dimensions. In particular, we investigate how burden sharing rules may impact the provision level of a public good that all agents voluntarily accept. We focus on different rulebased contribution mechanisms that are based on the principle of the smallest common denominator: all agents can suggest a minimum provision level of the public good that is allocated across agents according to some predetermined rule. The minimum of all proposals, i.e. the lowest common denominator, then creates a threshold for the own contribution. We introduced heterogeneity as our players differ with respect to their marginal benefit from the public good.

Our results indicate that rule-based contribution schemes significantly increase payoff levels relative to the voluntary contribution mechanism. Interestingly, the equal-payoff rule where the minimum threshold is chosen in a way that payoffs are equalized Pareto-dominates all other rules. This finding is particularly surprising since all rules are predicted to generate efficient, but differing allocations. Enforcing redistribution among heterogeneous players by equalizing payoffs performs best due to substantially higher contributions from high-type players. This holds in particular relative to the scheme where high- and low-type players separately can determine their minimum contribution: here, low-type agents end up contributing at the same rate as in the equal-payoff treatment while high-type agents fail to choose their predicted efficient minimum contribution level. This result may shed some light on the recent discussion in climate policy. In order to accelerate negotiations for a post-Kyoto agreement sub-agreements between rather homogenous countries are suggested. In our environment, these sub-agreements fail to produce efficiency. Instead, subjects with high marginal benefit contribute at a significantly higher level only when they know that the redistribution is explicitly enforced by the mechanisms.

Compared to the equal payoff-rule the performance of the single ("one for all”) smallest common denominator rule in our experiment is rather weak. While recent experiments have shown that this rule is quite successful under homogeneous players, we get a different picture 
under heterogeneity. This result underlines the importance of equity in the provision of public goods and of robustness checks for mechanisms under various conditions. Other aspects of heterogeneity such as heterogeneous costs, endowments or ways to generate the endowment ("house money effects") may alter the relative performance of the studied rule-based mechanisms. The experimental investigation of such heterogeneities on the performance of the different institutions and their possible adjustments are fruitful areas of further research. 


\section{References}

Anderson, L. R., J.M. Mellor, and J. Milyo (2008), Inequality and public good provision: An experimental analysis, Journal of Socio-Economics Vol. 37, 1010-1028.

Barrett, S. (2003), Environment and Statecraft: The strategy of Environmental Treaty-making, Oxford University Press, New York.

Bilodeau, M. and Gravel, N. (2004), Voluntary Provision of a Public Good and Individual Morality, Journal of Public Economics Vol. 88, 645-666.

Buckley, E., and R. Croson (2006), Income and wealth heterogeneity in the voluntary provision of linear public goods, Journal of Public Economics Vol 90(4-5), 935-955.

Chan, K., S. Mestelman, R. Moir, and R. A. Muller (1996), The voluntary provision of public goods under varying income distributions, Canadian Journal of Economics Vol. 70(2), 263-289.

Chan, K., S. Mestelman, R. Moir, and R. A. Muller (1999), Heterogeneity and the voluntary provision of public goods, Experimental Economics Vol. 2, 5-30.

Charness, G., and M. Rabin (2002), Understanding Social Preferences with Simple Tests, The Quarterly Journal of Economics Vol. 117(3), 817-869.

Cherry, T.L., S. Croll, and J.F. Shogren (2005), The impact of endowment heterogeneity and origin on public good contributions: Evidence from the lab, Journal of Economic Behavior and Organization Vol. 57, 357-365.

Dannenberg, A., A. Lange, and B. Sturm (2010), On the formation of coalitions to provide public goods - experimental evidence from the lab, NBER Working Paper No. 15967.

Fehr, E. and K.M. Schmidt (1999), A Theory of Fairness, Competition, and Cooperation, Quarterly Journal of Economics Vol. 114, 817-868.

Fellner, G. Y. Iida, S. Kröger, and E. Seki (2011), Heterogeneous Productivity in Voluntary Public Heterogeneous Productivity in Voluntary Public Good Provision : An Experimental Analysis, IZA Discussion Paper No. 5556.

Fischbacher, U. (2007), Z-Tree: Zurich Toolbox for Ready-made Economic Experiments, Experimental Economics Vol. 10(2), 171-178. 
Fisher, J., R. Isaac, J. Schatzberg, and J. Walker (1995), Heterogeneous Demand for Public Goods: Behavior in the Voluntary Contributions Mechanism, Public Choice Vol. 85, 249-266.

Georgantzis, N., and A. Proestakis (2011), Accounting for real wealth in heterogeneous public good games, ThE Discussion Papers No. 10/20, University of Granada.

Greiner, B. (2004), The Online Recruitment System ORSEE 2.0 - A Guide for the Organization of Experiments in Economics, Working Paper Series in Economics No. 10, University of Cologne.

Koukoumelis, A., M.V. Levati, and J. Weisser (2010), A voluntary contribution experiment with one-way communication and heterogeneity, Jena Economic Research Papers No. 2010-094.

Ledyard, J.O. (1995), Public Goods: A Survey of Experimental Research, in: Kagel, J. and A. Roth (eds.), The Handbook of Experimental Economics, Princeton University Press, Princeton, 111-194.

McGinty, M., G. Milam, and A. Gelves (fortcoming), Coalition Stability in Public Goods Provision: Testing an Optimal Allocation Rule, Environmental and Resource Economics.

Nordhaus, W.D. (2010), Economic aspects of global warming in a post-Copenhagen environment, Proceedings of the National Academy of Sciences 107, 11721-11726.

Olmstead, S.M. and R.N. Stavins (2006), An International Policy Architecture for the PostKyoto Era, The American Economic Review Vol. 96(2), 35-38.

Orzen, H. (2008), Fundraising through Competition: Evidence from the Lab, CeDEx Discussion Paper No. 2008-11, University of Nottingham.

Reuben, E., and A. Riedl (2009), Enforcement of Contribution Norms in Public Good Games with Heterogeneous Populations, IZA Discussion Paper No. 4303.

Sadrieh, A., and H. Verbon (2006), Inequality, cooperation, and growth: An experimental study, European Economic Review Vol. 50, 1197-1222.

Sato, T. (1987), Equity, Fairness and Lindahl Equilibria, Journal of Public Economics Vol. 33 ,

261-271. 
Silvestre, J. (1984), Voluntariness and Efficiency in the Provision of Public Goods, Journal of Public Economics Vol. 24, 257-270.

Spraggon, J., and R.J. Oxoby (2009), An experimental investigation of endowment source heterogeneity in two-person public good games, Economic Letters Vol. 104, 102-105.

Tan, F. (2008), Punishment in a Linear Public Good Game with Productivity Heterogeneity, De Economist Vol. 156, 269-293.

van Dijk, F., J. Sonnemans, and F. van Winden (2002), Social ties in a public good experiment, Journal of Public Economics Vol. 85, 275-299.

van den Nouweland, A., Tijs, S., and Wooders, M. (2002), Axiomatization of Ratio Equilibria in Public Good Economies, Social Choice and Welfare Vol. 19, 627-636.

Zelmer, J. (2003), Linear Public Good Experiments: A Meta-Analysis, Experimental Economics Vol. 6, 299-310. 


\section{Appendix}

Table 1: Summary of predictions with standard preferences

\begin{tabular}{|l|c|c|c|c|c|c|}
\hline & $q_{i, \text { low }}$ & $q_{\text {i,high }}$ & $\pi_{i, \text { low }}$ & $\pi_{i, \text { high }}$ & $\Pi$ & $\pi_{\text {all }}$ \\
\hline VCM & 0 & 0 & 20 & 20 & 80 & 20 \\
\hline min-I-q & 20 & 20 & 24 & 56 & 160 & 40 \\
\hline min-II- $q$ & 0 & 20 & 32 & 28 & 120 & 30 \\
\hline min-I-Q & 20 & 20 & 24 & 56 & 160 & 40 \\
\hline min-I-Q-eq & 2.2 & 19.8 & 31 & 31 & 124 & 31 \\
\hline
\end{tabular}

Table 2: Summary of experimental design

\begin{tabular}{|c|c|c|c|c|c|}
\hline Treatment & Stages & $\begin{array}{l}\text { Separated minimum rules for low- } \\
\text { type and high-type players }\end{array}$ & $n$ & $b_{i}$ & $\begin{array}{l}\text { No. of subjects } \\
\text { (ind. obs.) }\end{array}$ \\
\hline VCM & contribution & & 4 & $\begin{array}{l}b_{i, \text { low }}=0.3 \\
b_{i, \text { high }} \\
=0.7\end{array}$ & 48 (12) \\
\hline $\min -I-q$ & $\begin{array}{c}\text { minimum } \\
\text { contribution }\end{array}$ & no & 4 & $\begin{array}{l}b_{i, \text { low }}=0.3 \\
b_{i, \text { high }} \\
=0.7\end{array}$ & 72 (18) \\
\hline $\min -I I-q$ & $\begin{array}{l}\text { minimum } \\
\text { contribution }\end{array}$ & yes & 4 & $\begin{array}{l}b_{i, \text { low }}=0.3 \\
b_{i, \text { high }} \\
=0.7\end{array}$ & 72 (18) \\
\hline $\min -I-Q$ & $\begin{array}{c}\text { minimum } \\
\text { contribution }\end{array}$ & no & 4 & $\begin{array}{l}b_{i, \text { low }}=0.3 \\
b_{i, \text { high }} \\
=0.7\end{array}$ & 68 (17) \\
\hline min-I-Q-eq & $\begin{array}{c}\text { minimum } \\
\text { contribution }\end{array}$ & yes & 4 & $\begin{array}{l}b_{i, \text { low }}=0.3 \\
b_{i, \text { high }} \\
=0.7\end{array}$ & 72 (18) \\
\hline
\end{tabular}

Table 3: Summary statistics for all treatments

\begin{tabular}{|c|c|c|c|c|c|c|c|c|c|}
\hline Treatment & $q_{\text {all }}$ & $q_{\text {low }}$ & $q_{\text {high }}$ & $q_{\text {ratio }}$ & $\pi_{\text {low }}$ & $\pi_{\text {high }}$ & $\pi_{\text {ratio }}$ & $\Pi$ & $\pi_{\text {all }}$ \\
\hline & \multicolumn{9}{|c|}{ All periods } \\
\hline$V C M$ & 5.5 & 3.2 & 7.7 & 2.41 & 23.33 & 27.59 & 1.18 & 101.84 & 25.46 \\
\hline $\min -I-q$ & 6.4 & 5.8 & 7.3 & 1.26 & 22.05 & 31.10 & 1.41 & 106.29 & 26.57 \\
\hline $\min -I I-q$ & 7.2 & 4.5 & 9.9 & 2.20 & 24.13 & 30.21 & 1.25 & 108.68 & 27.17 \\
\hline $\min -I-Q$ & 7.4 & 6.3 & 8.4 & 1.33 & 22.54 & 32.37 & 1.44 & 109.28 & 27.32 \\
\hline \multirow[t]{2}{*}{ min-I-Q-eq } & 9.4 & 3.6 & 15.1 & 4.19 & 27.65 & 31.02 & 1.12 & 117.34 & 29.34 \\
\hline & \multicolumn{9}{|c|}{ Periods 1-5 } \\
\hline$V C M$ & 7.0 & 4.4 & 9.6 & 2.18 & 23.97 & 30.05 & 1.25 & 108.05 & 27.01 \\
\hline $\min -I-q$ & 6.8 & 5.9 & 7.6 & 1.29 & 22.19 & 31.35 & 1.41 & 107.07 & 26.77 \\
\hline $\min -I I-q$ & 7.6 & 5.2 & 9.9 & 1.90 & 23.82 & 31.27 & 1.31 & 110.17 & 27.54 \\
\hline $\min -I-Q$ & 7.9 & 6.4 & 9.3 & 1.45 & 23.01 & 32.64 & 1.42 & 111.29 & 27.82 \\
\hline \multirow[t]{2}{*}{$\min -I-Q-e q$} & 8.8 & 3.7 & 13.8 & 3.73 & 26.79 & 30.73 & 1.15 & 115.04 & 28.76 \\
\hline & \multicolumn{9}{|c|}{ Periods 6-10 } \\
\hline$V C M$ & 3.9 & 2.0 & 5.8 & 2.90 & 22.69 & 25.13 & 1.11 & 95.63 & 23.91 \\
\hline $\min -I-q$ & 6.4 & 5.7 & 7.0 & 1.23 & 21.91 & 30.85 & 1.41 & 105.51 & 26.38 \\
\hline $\min -I I-q$ & 6.8 & 3.7 & 9.9 & 2.68 & 24.45 & 29.14 & 1.19 & 107.19 & 26.80 \\
\hline $\min -I-Q$ & 6.9 & 6.2 & 7.5 & 1.21 & 22.06 & 32.10 & 1.46 & 107.26 & 26.82 \\
\hline $\min -I-Q-e q$ & 9.9 & 3.4 & 16.4 & 4.82 & 28.51 & 31.32 & 1.10 & 119.65 & 29.91 \\
\hline
\end{tabular}

Notes: $q_{\text {all }}=$ average contribution per group, $q_{\text {low }}=$ average contributions for low-type, $q_{\text {high }}=$ average contributions for high-type, $q_{\text {ratio }}=q_{\text {high }} / q_{\text {low }}, \pi_{\text {low }}=$ average profits for low-type, $\pi_{\text {high }}=$ average profits for high-type, $\pi_{\text {ratio }}=\pi_{\text {high }} / \pi_{\text {low }}$, $\Pi=$ sum of profits for all players, $\pi_{\text {all }}=$ average profit per group. 
Table 4: Tests between treatments (MW U test)

\begin{tabular}{|c|c|c|c|c|c|c|c|c|}
\hline Treatment & $V C M$ & $\min -I-q$ & $\min -I I-q$ & $\min -I-Q$ & $V C M$ & $\min -I-q$ & $\min -I I-q$ & $\min -I-Q$ \\
\hline$q_{i}$ all players & \multicolumn{4}{|c|}{ Period 1-10 } & \multicolumn{4}{|c|}{ Period 6-10 } \\
\hline $\min -I-q$ & $>$ & & & & $>* *$ & & & \\
\hline $\min -I I-q$ & $>$ & $>$ & & & $>* * *$ & $>$ & & \\
\hline $\min -I-Q$ & $>$ & $>$ & $>$ & & $>* * *$ & $>$ & $>$ & \\
\hline min-I-Q-eq & $>* * *$ & $>* *$ & $>* * *$ & $>*$ & $>* * *$ & $>* * *$ & $>* * *$ & $>* * *$ \\
\hline Treatment & $V C M$ & $\min -I-q$ & $\min -I I-q$ & $\min -I-Q$ & $V C M$ & $\min -I-q$ & $\min -I I-q$ & $\min -I-Q$ \\
\hline$q_{\text {low }}$ & \multicolumn{4}{|c|}{ Period 1-10 } & \multicolumn{4}{|c|}{ Period 6-10 } \\
\hline $\min -I-q$ & $* *$ & & & & $>* * *$ & & & \\
\hline $\min -I I-q$ & $>$ & $<$ & & & $>* * *$ & $<* * *$ & & \\
\hline $\min -I-Q$ & $>* *$ & $>$ & $>*$ & & $>* * *$ & $>$ & $>* * *$ & \\
\hline min-I-Q-eq & $>$ & $<* *$ & $<$ & $<* * *$ & $>* * *$ & $<* * *$ & $<$ & $<* * *$ \\
\hline Treatment & VCM & $\min -I-q$ & $\min -I I-q$ & $\min -I-Q$ & VCM & $\min -I-q$ & $\min -I I-q$ & $\min -I-Q$ \\
\hline $\boldsymbol{q}_{\text {high }}$ & \multicolumn{4}{|c|}{ Period 1-10 } & \multicolumn{4}{|c|}{ Period 6-10 } \\
\hline $\min -I-q$ & $<$ & & & & $>$ & & & \\
\hline $\min -I I-q$ & $>$ & $>*$ & & & $>* * *$ & $>* * *$ & & \\
\hline $\min -I-Q$ & $>$ & $>$ & $<$ & & $>$ & $>$ & $<* * *$ & \\
\hline min-I-Q-eq & $>* * *$ & $>* * *$ & $>* * *$ & $>* * *$ & $>* * *$ & $>* * *$ & $>* * *$ & $>* * *$ \\
\hline Treatment & $V C M$ & $\min -I-q$ & $\min -I I-q$ & $\min -I-Q$ & $V C M$ & $\min -I-q$ & $\min -I I-q$ & $\min -I-Q$ \\
\hline$\pi_{\mathrm{i}}$ all players & \multicolumn{4}{|c|}{ Period 1-10 } & \multicolumn{4}{|c|}{ Period 6-10 } \\
\hline $\min -I-q$ & $>$ & & & & $>* *$ & & & \\
\hline $\min -I I-q$ & $>$ & $>$ & & & $>* * *$ & $>$ & & \\
\hline $\min -I-Q$ & $>$ & $>$ & $>$ & & $>* * *$ & $>$ & $>$ & \\
\hline min-I-Q-eq & $>* *$ & $>* *$ & $>* * *$ & $>*$ & $>* * *$ & $>* * *$ & $>* * *$ & $>* * *$ \\
\hline Treatment & $V C M$ & $\min -I-q$ & $\min -I I-q$ & $\min -I-Q$ & $V C M$ & $\min -I-q$ & $\min -I I-q$ & $\min -I-Q$ \\
\hline$\pi_{\text {low }}$ & \multicolumn{4}{|c|}{ Period 1-10 } & \multicolumn{4}{|c|}{ Period 6-10 } \\
\hline $\min -I-q$ & $<$ & & & & $<$ & & & \\
\hline $\min -I I-q$ & $>$ & $>* * *$ & & & $>* * *$ & $>* * *$ & & \\
\hline $\min -I-Q$ & $<$ & $>$ & $<* *$ & & $<$ & $>$ & $<* * *$ & \\
\hline min-I-Q-eq & $>* * *$ & $>* * *$ & $>* * *$ & $>* * *$ & $>* * *$ & $>* * *$ & $>* * *$ & $>* * *$ \\
\hline Treatment & $V C M$ & $\min -I-q$ & $\min -I I-q$ & $\min -I-Q$ & $V C M$ & $\min -I-q$ & $\min -I I-q$ & $\min -I-Q$ \\
\hline$\pi_{\text {high }}$ & \multicolumn{4}{|c|}{ Period 1-10 } & \multicolumn{4}{|c|}{ Period 6-10 } \\
\hline $\min -I-q$ & $>$ & & & & $>* * *$ & & & \\
\hline $\min -I I-q$ & $>$ & $<$ & & & $>* * *$ & $<$ & & \\
\hline $\min -I-Q$ & $>* *$ & $>$ & $>$ & & $>* * *$ & $>$ & $>* *$ & \\
\hline min-I-Q-eq & $>* *$ & $<$ & $>$ & $<$ & $>* * *$ & $>* * *$ & $>* * *$ & $<$ \\
\hline
\end{tabular}

Note: We compare rows with columns. ${ }^{* * *} \mathrm{p}<0.01,{ }^{* *} \mathrm{p}<0.05,{ }^{*} \mathrm{p}<0.1$ 


\begin{tabular}{|c|c|c|c|c|c|}
\hline VARIABLES & $\begin{array}{c}(1) \\
\text { All per. } \\
\text { Profit }\end{array}$ & $\begin{array}{c}(2) \\
\text { All per. } \\
\text { Profit }\end{array}$ & $\begin{array}{c}(3) \\
\text { All per. } \\
\text { Profit } \\
\end{array}$ & $\begin{array}{c}(4) \\
\text { All per. } \\
\text { Profit }\end{array}$ & $\begin{array}{c}(5) \\
\text { Last } 5 \text { per. } \\
\text { Profit }\end{array}$ \\
\hline min_I_q & $\begin{array}{c}1.112 \\
(0.995)\end{array}$ & $\begin{array}{c}-0.246 \\
(1.118)\end{array}$ & $\begin{array}{c}-2.642 * * * \\
(0.792)\end{array}$ & $\begin{array}{c}-1.787 * * \\
(0.747)\end{array}$ & $\begin{array}{l}-0.781 \\
(0.542)\end{array}$ \\
\hline min_II_q & $\begin{array}{l}1.709 * \\
(0.911)\end{array}$ & $\begin{array}{c}0.529 \\
(1.115)\end{array}$ & $\begin{array}{l}-0.378 \\
(0.780)\end{array}$ & $\begin{array}{l}-0.157 \\
(0.747)\end{array}$ & $\begin{array}{l}1.761^{* * *} \\
(0.733)\end{array}$ \\
\hline min_I_Q & $\begin{array}{l}1.991^{*} \\
(1.016)\end{array}$ & $\begin{array}{c}0.811 \\
(1.238)\end{array}$ & $\begin{array}{c}-1.976 * * \\
(0.873)\end{array}$ & $\begin{array}{l}-0.962 \\
(0.748)\end{array}$ & $\begin{array}{l}-0.630 \\
(0.611)\end{array}$ \\
\hline min_I_Q_eq & $\begin{array}{c}3.876 * * * \\
(0.778)\end{array}$ & $\begin{array}{l}1.747^{*} \\
(0.993)\end{array}$ & $\begin{array}{c}2.185 * * * \\
(0.770)\end{array}$ & $\begin{array}{c}2.813^{* * * *} \\
(0.750)\end{array}$ & $\begin{array}{c}5.815^{* * *} \\
(0.642)\end{array}$ \\
\hline per6_10_VCM & & $\begin{array}{c}-3.104^{* * *} \\
(0.637)\end{array}$ & $\begin{array}{c}-3.104^{* * * *} \\
(0.638)\end{array}$ & $\begin{array}{c}-1.283^{* * *} \\
(0.392)\end{array}$ & \\
\hline per6_10_min_I_q & & $\begin{array}{l}-0.389 \\
(0.659)\end{array}$ & $\begin{array}{l}-0.389 \\
(0.660)\end{array}$ & $\begin{array}{l}-0.278 \\
(0.381)\end{array}$ & \\
\hline per6_10_min_II_q & & $\begin{array}{l}-0.744 \\
(0.495)\end{array}$ & $\begin{array}{l}-0.744 \\
(0.495)\end{array}$ & $\begin{array}{c}0.634 \\
(0.522)\end{array}$ & \\
\hline per6_10_min_I_Q & & $\begin{array}{l}-0.744 \\
(0.948)\end{array}$ & $\begin{array}{l}-0.744 \\
(0.949)\end{array}$ & $\begin{array}{c}-0.952^{* *} \\
(0.393)\end{array}$ & \\
\hline per6_10_min_I_Q_eq & & $\begin{array}{l}1.154^{* *} \\
(0.523)\end{array}$ & $\begin{array}{l}1.154^{* *} \\
(0.523)\end{array}$ & $\begin{array}{c}1.719 * * * \\
(0.503)\end{array}$ & \\
\hline high_VCM & & & $\begin{array}{c}4.257 * * * \\
(1.028)\end{array}$ & $\begin{array}{c}6.078 * * * \\
(1.320)\end{array}$ & $\begin{array}{c}2.437 * * \\
(1.024)\end{array}$ \\
\hline high_min_I_q & & & $\begin{array}{c}9.049 * * * \\
(1.178)\end{array}$ & $\begin{array}{c}9.160 * * * \\
(1.151)\end{array}$ & $\begin{array}{c}8.938^{* * * *} \\
(1.525)\end{array}$ \\
\hline high_min_II_q & & & $\begin{array}{c}6.071 * * * \\
(1.175)\end{array}$ & $\begin{array}{c}7.450^{* * *} \\
(1.300)\end{array}$ & $\begin{array}{c}4.692 * * * \\
(1.229)\end{array}$ \\
\hline high_min_I_Q & & & $\begin{array}{c}9.831 * * * \\
(1.129)\end{array}$ & $\begin{array}{c}9.624 * * * \\
(1.500)\end{array}$ & $\begin{array}{c}10.04^{* * *} \\
(1.451)\end{array}$ \\
\hline high_min_I_Q_eq & & & $\begin{array}{c}3.381 * * * \\
(0.912)\end{array}$ & $\begin{array}{c}3.945^{* * * *} \\
(1.104)\end{array}$ & $\begin{array}{c}2.816^{* * *} \\
(0.993)\end{array}$ \\
\hline high_per6_10_VCM & & & & $\begin{array}{c}-3.642 * * * \\
(1.162)\end{array}$ & \\
\hline high_per6_10_min_I_q & & & & $\begin{array}{c}-0.222 \\
(1.320)\end{array}$ & \\
\hline high_per6_10_min_II_q & & & & $\begin{array}{c}-2.758^{* * *} \\
(0.936)\end{array}$ & \\
\hline high_per6_10_min_I_Q & & & & $\begin{array}{c}0.415 \\
(1.899)\end{array}$ & \\
\hline high_per6_10_min_I_Q_eq & & & & $\begin{array}{l}-1.129 \\
(1.039)\end{array}$ & \\
\hline Constant & $\begin{array}{c}25.46 * * * \\
(0.598)\end{array}$ & $\begin{array}{c}27.01 * * * \\
(0.792)\end{array}$ & $\begin{array}{c}24.88 * * * \\
(0.607)\end{array}$ & $\begin{array}{c}23.97 * * * \\
(0.577)\end{array}$ & $\begin{array}{c}22.69 * * * \\
(0.473)\end{array}$ \\
\hline Observations & 3,320 & 3,320 & 3,320 & 3,320 & 1,660 \\
\hline R-sq & 0.0253 & 0.0334 & 0.2453 & 0.2494 & 0.2419 \\
\hline
\end{tabular}


Definition of variables

\begin{tabular}{|l|l|}
\hline qi & Subject's contribution \\
\hline Profit & Subject's payoff \\
\hline min_I_q & $=1$ if subject played treatment min-I-q, 0 otherwise \\
\hline min_II_q & $=1$ if subject played treatment min-II-q, 0 otherwise \\
\hline min_I_Q & $=1$ if subject played treatment min-I-Q, 0 otherwise \\
\hline min_I_Q_eq & $=1$ if subject played treatment min-I-Q-eq, 0 otherwise \\
\hline per6_10_*treatment* & $=1$ for the last 5 periods and subject played *treatment*, 0 otherwise \\
\hline high_*treatment* & $=1$ if subject played *treatment* and is a high-type, 0 otherwise \\
\hline high_per6_10_*treatment* & $\begin{array}{l}=1 \text { for the last } 5 \text { periods and subject is a high-type and subject played *treatment*, } 0 \\
\text { otherwise }\end{array}$ \\
\hline
\end{tabular}




\begin{tabular}{|c|c|c|c|c|c|}
\hline VARIABLES & $\begin{array}{c}(1) \\
\text { All per. } \\
\text { qi } \\
\end{array}$ & $\begin{array}{c}\text { (2) } \\
\text { All per. } \\
\text { qi } \\
\end{array}$ & $\begin{array}{c}\text { (3) } \\
\text { All per. } \\
\text { qi } \\
\end{array}$ & $\begin{array}{c}\text { (4) } \\
\text { All per. } \\
\text { qi }\end{array}$ & $\begin{array}{c}5) \\
\text { Last } 5 \text { per. } \\
\text { qi } \\
\end{array}$ \\
\hline min_I_q & $\begin{array}{c}1.112 \\
(0.793)\end{array}$ & $\begin{array}{l}-0.246 \\
(0.912)\end{array}$ & $\begin{array}{c}1.260 \\
(0.859)\end{array}$ & $\begin{array}{l}1.492 * \\
(0.895)\end{array}$ & $\begin{array}{c}3.744 * * * \\
(0.969)\end{array}$ \\
\hline min_II_q & $\begin{array}{l}1.709^{* *} \\
(0.851)\end{array}$ & $\begin{array}{c}0.529 \\
(0.963)\end{array}$ & $\begin{array}{l}0.0687 \\
(0.953)\end{array}$ & $\begin{array}{c}0.792 \\
(0.993)\end{array}$ & $\begin{array}{l}1.706 * * \\
(0.846)\end{array}$ \\
\hline min_I_Q & $\begin{array}{l}1.859^{* *} \\
(0.778)\end{array}$ & $\begin{array}{c}0.811 \\
(0.980)\end{array}$ & $\begin{array}{l}2.002^{* *} \\
(0.991)\end{array}$ & $\begin{array}{l}1.935^{*} \\
(1.085)\end{array}$ & $\begin{array}{c}4.165^{* * * *} \\
(0.945)\end{array}$ \\
\hline min_I_Q_eq & $\begin{array}{c}3.876^{* * *} \\
(0.999)\end{array}$ & $\begin{array}{c}1.747 \\
(1.069)\end{array}$ & $\begin{array}{c}-1.792^{* *} \\
(0.858)\end{array}$ & $\begin{array}{l}-0.717 \\
(0.908)\end{array}$ & $\begin{array}{l}1.391 * \\
(0.722)\end{array}$ \\
\hline per6_10_VCM & & $\begin{array}{c}-3.104 * * * \\
(0.520)\end{array}$ & $\begin{array}{c}-3.104^{* * * *} \\
(0.520)\end{array}$ & $\begin{array}{c}-2.442^{* * * *} \\
(0.617)\end{array}$ & \\
\hline per6_10_min_I_q & & $\begin{array}{l}-0.389 \\
(0.542)\end{array}$ & $\begin{array}{l}-0.389 \\
(0.543)\end{array}$ & $\begin{array}{l}-0.189 \\
(0.754)\end{array}$ & \\
\hline per6_10_min_II_q & & $\begin{array}{l}-0.744 \\
(0.508)\end{array}$ & $\begin{array}{l}-0.744 \\
(0.508)\end{array}$ & $\begin{array}{c}-1.528 * * * \\
(0.425)\end{array}$ & \\
\hline per6_10_min_I_Q & & $\begin{array}{l}-1.009 \\
(0.787)\end{array}$ & $\begin{array}{l}-1.009 \\
(0.788)\end{array}$ & $\begin{array}{c}-0.212 \\
(0.999)\end{array}$ & \\
\hline per6_10_min_I_Q_eq & & $\begin{array}{l}1.154^{* *} \\
(0.552)\end{array}$ & $\begin{array}{l}1.154^{* *} \\
(0.552)\end{array}$ & $\begin{array}{l}-0.334 \\
(0.490)\end{array}$ & \\
\hline high_VCM & & & $\begin{array}{c}4.479 * * * \\
(1.036)\end{array}$ & $\begin{array}{c}5.142 * * * \\
(1.266)\end{array}$ & $\begin{array}{c}3.817 * * * \\
(1.035)\end{array}$ \\
\hline high_min_I_q & & & $\begin{array}{c}1.467 \\
(0.998)\end{array}$ & $\begin{array}{c}1.667 \\
(1.068)\end{array}$ & $\begin{array}{c}1.267 \\
(1.201)\end{array}$ \\
\hline high_min_II_q & & & $\begin{array}{c}5.400 * * * \\
(1.003)\end{array}$ & $\begin{array}{c}4.617 * * * \\
(1.124)\end{array}$ & $\begin{array}{c}6.183^{* * * *} \\
(1.118)\end{array}$ \\
\hline high_min_I_Q & & & $\begin{array}{l}2.097 * * \\
(0.931)\end{array}$ & $\begin{array}{c}2.894 * * \\
(1.253)\end{array}$ & $\begin{array}{c}1.300 \\
(1.179)\end{array}$ \\
\hline high_min_I_Q_eq & & & $\begin{array}{c}11.56 * * * \\
(0.800)\end{array}$ & $\begin{array}{c}10.07 * * * \\
(1.005)\end{array}$ & $\begin{array}{c}13.04 * * * \\
(0.905)\end{array}$ \\
\hline high_per6_10_VCM & & & & $\begin{array}{l}-1.325 \\
(1.024)\end{array}$ & \\
\hline high_per6_10_min_I_q & & & & $\begin{array}{c}-0.400 \\
(1.085)\end{array}$ & \\
\hline high_per6_10_min_II_q & & & & $\begin{array}{l}1.567 \\
(1.000)\end{array}$ & \\
\hline high_per6_10_min_I_Q & & & & $\begin{array}{l}-1.594 \\
(1.565)\end{array}$ & \\
\hline high_per6_10_min_I_Q_eq & & & & $\begin{array}{c}2.976 * * * \\
(1.047)\end{array}$ & \\
\hline Constant & $\begin{array}{c}5.460 * * * \\
(0.610)\end{array}$ & $\begin{array}{c}7.013 * * * \\
(0.733)\end{array}$ & $\begin{array}{c}4.773^{* * *} \\
(0.594)\end{array}$ & $\begin{array}{c}4.442^{* * *} \\
(0.663)\end{array}$ & $\begin{array}{c}2 * * * \\
(0.454)\end{array}$ \\
\hline Observations & 3,320 & 3,320 & 3,320 & 3,320 & 1,660 \\
\hline R-sq & 0.0328 & 0.0439 & 0.2593 & 0.2637 & 0.3155 \\
\hline
\end{tabular}


Table 6b: Tobit Random-effects regression of contributions to the public good

\begin{tabular}{|c|c|c|c|c|c|}
\hline VARIABLES & $\begin{array}{c}(1) \\
\text { All per. } \\
\text { qi }\end{array}$ & $\begin{array}{c}(2) \\
\text { All per. } \\
\text { qi } \\
\end{array}$ & $\begin{array}{c}\text { (3) } \\
\text { All per. } \\
\text { qi } \\
\end{array}$ & $\begin{array}{c}(4) \\
\text { All per. } \\
\text { qi } \\
\end{array}$ & $\begin{array}{c}\text { (5) } \\
\text { Last } 5 \text { per. } \\
\text { qi }\end{array}$ \\
\hline min_I_q & $\begin{array}{c}2.601 * * \\
(1.262)\end{array}$ & $\begin{array}{c}0.696 \\
(1.316)\end{array}$ & $\begin{array}{l}2.860^{*} \\
(1.487)\end{array}$ & $\begin{array}{l}2.811^{*} \\
(1.530)\end{array}$ & $\begin{array}{c}7.062 * * * \\
(1.817)\end{array}$ \\
\hline min_II_q & $\begin{array}{c}3.152^{* *} \\
(1.262)\end{array}$ & $\begin{array}{c}1.544 \\
(1.317)\end{array}$ & $\begin{array}{c}0.875 \\
(1.491)\end{array}$ & $\begin{array}{c}1.666 \\
(1.534)\end{array}$ & $\begin{array}{c}3.789 * * \\
(1.824)\end{array}$ \\
\hline min_I_Q & $\begin{array}{c}3.470^{* * *} \\
(1.277)\end{array}$ & $\begin{array}{c}1.917 \\
(1.332)\end{array}$ & $\begin{array}{l}3.583 * * \\
(1.507)\end{array}$ & $\begin{array}{l}3.158^{* *} \\
(1.552)\end{array}$ & $\begin{array}{c}7.742^{* * *} \\
(1.835)\end{array}$ \\
\hline min_I_Q_eq & $\begin{array}{c}6.738 * * * \\
(1.263)\end{array}$ & $\begin{array}{c}3.608 * * * \\
(1.317)\end{array}$ & $\begin{array}{l}0.0621 \\
(1.487)\end{array}$ & $\begin{array}{l}1.093 \\
(1.530)\end{array}$ & $\begin{array}{c}5.866^{* * * *} \\
(1.811)\end{array}$ \\
\hline per6_10_VCM & & $\begin{array}{c}-4.919 * * * \\
(0.623)\end{array}$ & $\begin{array}{c}-4.861 * * * \\
(0.617)\end{array}$ & $\begin{array}{c}-4.737 * * * \\
(0.907)\end{array}$ & \\
\hline per6_10_min_I_q & & $\begin{array}{l}-0.790 * \\
(0.472)\end{array}$ & $\begin{array}{l}-0.776^{*} \\
(0.469)\end{array}$ & $\begin{array}{c}-0.582 \\
(0.661)\end{array}$ & \\
\hline per6_10_min_II_q & & $\begin{array}{c}-1.402^{* * *} \\
(0.477)\end{array}$ & $\begin{array}{c}-1.406 * * * \\
(0.475)\end{array}$ & $\begin{array}{c}-2.987 * * * \\
(0.694)\end{array}$ & \\
\hline per6_10_min_I_Q & & $\begin{array}{c}-1.504^{* * *} \\
(0.487)\end{array}$ & $\begin{array}{c}-1.491 * * * \\
(0.485)\end{array}$ & $\begin{array}{l}-0.536 \\
(0.689)\end{array}$ & \\
\hline per6_10_min_I_Q_eq & & $\begin{array}{c}1.640^{* * *} \\
(0.469)\end{array}$ & $\begin{array}{c}1.655^{* * *} \\
(0.469)\end{array}$ & $\begin{array}{l}-0.320 \\
(0.645)\end{array}$ & \\
\hline high_VCM & & & $\begin{array}{c}6.481^{* * *} \\
(1.586)\end{array}$ & $\begin{array}{c}6.568 * * * \\
(1.678)\end{array}$ & $\begin{array}{c}6.869 * * * \\
(1.980)\end{array}$ \\
\hline high_min_I_q & & & $\begin{array}{c}1.941 \\
(1.270)\end{array}$ & $\begin{array}{c}2.124 \\
(1.350)\end{array}$ & $\begin{array}{c}1.988 \\
(1.552)\end{array}$ \\
\hline high_min_II_q & & & $\begin{array}{c}7.545^{* * *} \\
(1.274)\end{array}$ & $\begin{array}{c}6.098^{* * *} * \\
(1.352)\end{array}$ & $\begin{array}{c}9.221 * * * \\
(1.560)\end{array}$ \\
\hline high_min_I_Q & & & $\begin{array}{c}2.933^{* *} \\
(1.309)\end{array}$ & $\begin{array}{c}3.847 * * * \\
(1.392)\end{array}$ & $\begin{array}{c}1.899 \\
(1.592)\end{array}$ \\
\hline high_min_I_Q_eq & & & $\begin{array}{c}13.32 * * * \\
(1.272)\end{array}$ & $\begin{array}{c}11.28 * * * \\
(1.350)\end{array}$ & $\begin{array}{c}15.61 * * * \\
(1.555)\end{array}$ \\
\hline high_per6_10_VCM & & & & $\begin{array}{l}-0.215 \\
(1.231)\end{array}$ & \\
\hline high_per6_10_min_I_q & & & & $\begin{array}{l}-0.381 \\
(0.933)\end{array}$ & \\
\hline high_per6_10_min_II_q & & & & $\begin{array}{c}2.976 * * * \\
(0.949)\end{array}$ & \\
\hline high_per6_10_min_I_Q & & & & $\begin{array}{l}-1.859 * \\
(0.963)\end{array}$ & \\
\hline high_per6_10_min_I_Q_eq & & & & $\begin{array}{c}4.128^{* * *} \\
(0.934)\end{array}$ & \\
\hline Constant & $\begin{array}{c}3.184 * * * \\
(0.984)\end{array}$ & $\begin{array}{c}5.490^{* * *} \\
(1.025)\end{array}$ & $\begin{array}{c}2.385^{* *} \\
(1.164)\end{array}$ & $\begin{array}{l}2.346^{*} \\
(1.197)\end{array}$ & $\begin{array}{l}-2.724^{*} \\
(1.450)\end{array}$ \\
\hline Observations & 3,320 & 3,320 & 3,320 & 3,320 & 1,660 \\
\hline
\end{tabular}


Figure 1: Mean contributions over time
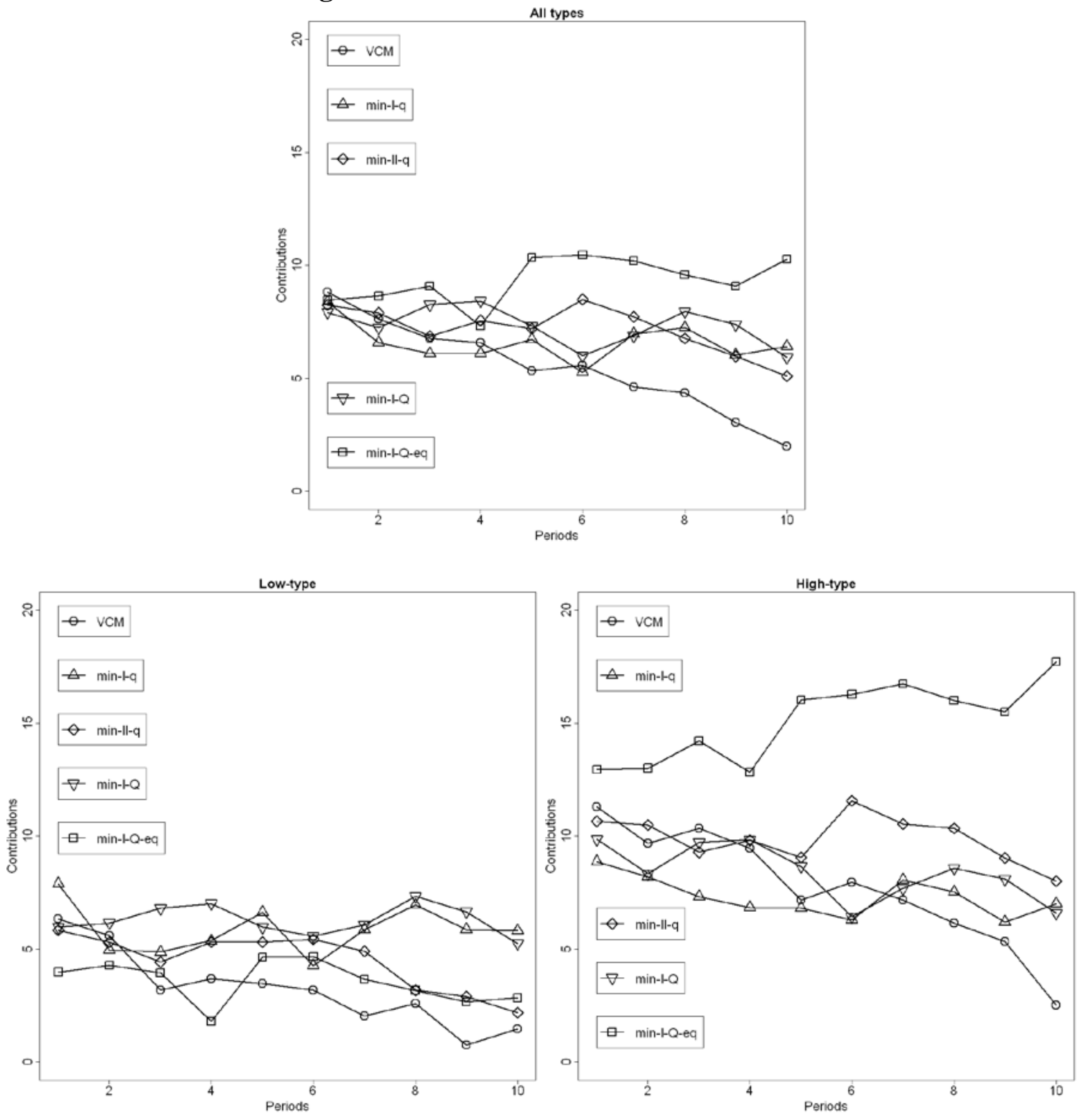
Figure 2: Mean profits over time
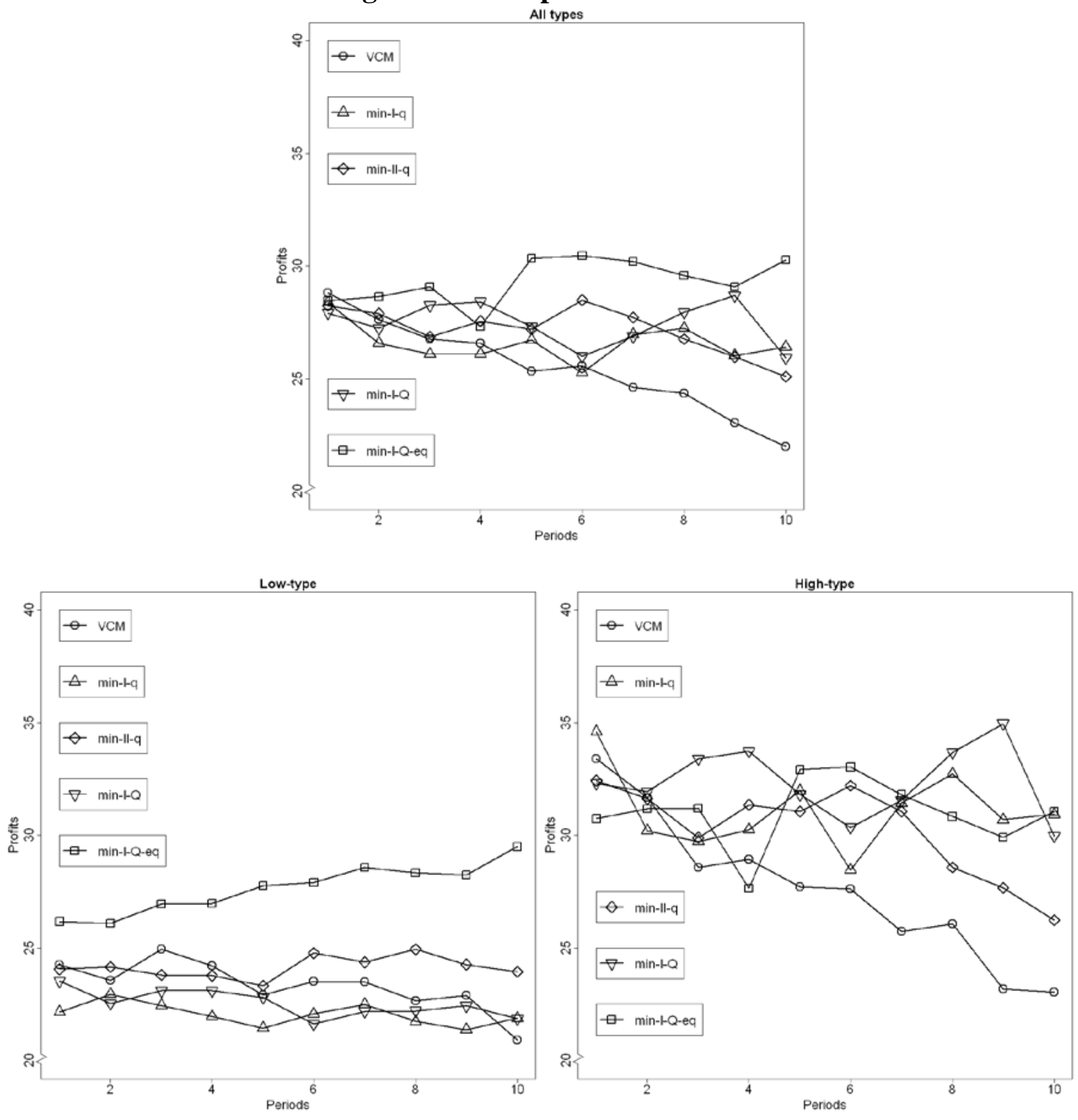
Figure 3: Profits per group (average over periods 6 to 10)

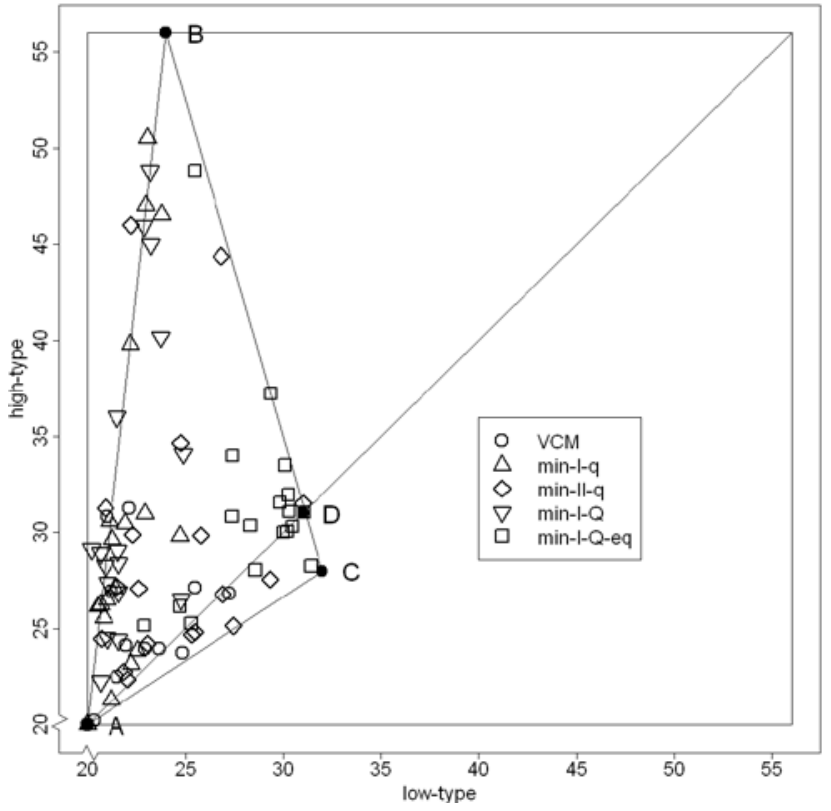




\section{Experimental instructions for min-I-Q-eq treatment}

\section{Instructions}

Welcome to the Magdeburg Experimental Laboratory MaXLab!

Please read these instructions carefully and should you have any questions please signal us by opening the door or a show of hands. Please do not talk to other participants.

In the laboratory experiment you are taking part in, you can win money depending on your decisions and the decisions of your fellow players. Your payout from the experiment will be calculated in LabDollars (LD). The conversion rate between $€$ and LD is 1:2.5, i.e. 1 LD are $0.40 €$. All your decisions made in the experiment will remain anonymous. Only the experimenter will know your identity, but your data will be treated confidentially.

\section{Rules of the game}

Now you will learn more about the rules of the game you will be participating in. Altogether 4 players take part in the game, so besides you there are 3 more players. Each player has an initial endowment of 20 points. Your task in the game, and also your fellow players' task, is to decide how many points you would like to contribute to a joint project. Your contribution, q, can be set between 0 and 20 points.

Your individual and also your fellow players' payout will be calculated as follows:

Your payout $=(20-$ your contribution to the project $)+b$ (sum of all contributions of all players to the project)

The parameter $b$ is $b=0.3$ for two players (in the following called "low-type") and $b=0.7$ for the remaining two players (in the following called "high-type"). There will be a random selection whether you are a low-type or a high-type.

Assuming you to be a low-type: Your payout (in LD) will be calculated as follows:

Payout $=(20-$ your contribution to the project $)+0.3 \cdot($ sum of all contributions of all players to the project)

That is, if for example all other players have contributed altogether 60 points to the project and your contribution is 20 , then your payment will be:

$$
\text { Payout }=(20-20)+0.3 \cdot(60+20)=24
$$

If, however, all other players have contributed a total amount of 60 points and you do not contribute anything, your payout will be:

$$
\text { Payout }=(20-0)+0,3 \cdot(60+0)=38
$$

If you are a high-type, then your payout (in LD) will be calculated as follows: 
Payout $=(20-$ your contribution to the project $)+0.7 \cdot($ sum of all contributions of all players to the project)

The information, whether you are a low-or a high-Type will be displayed on your screen.

There are two stages in this game. In stage 1 you decide on the minimum contribution, $\mathrm{Q}_{\text {min, }}$ that should be contributed to the joint project by the group as a whole. Simultaneously, all other players make their suggestions on a group minimum contribution level, $\mathrm{Q}_{\min }$. The minimum of the suggested levels, $\min \left(Q_{\min }\right)$, is then decisive for contributions in the second stage. In stage 2 you decide on your contribution, q, to the joint project, thereby keeping in mind that for each player an individual minimum contribution level, $\mathrm{q}_{\min }$, will be calculated from $\min \left(\mathrm{Q}_{\min }\right)$. The implementation of these individual minimum contributions, $\mathrm{q}_{\min }$, yields to equal payoffs for all players or payoffs will at least be harmonized as far as possible if a player faces $\mathrm{q}_{\min }=20$.

Example: If the group minimum contribution level is $\mathrm{Q}_{\min }=40$, low-type players are bounded to an individual minimum contribution of $\mathrm{q}_{\min }=2$ and high-type agents face $\mathrm{q}_{\min }=18$. Assuming these contribution levels, the payoff for each player would be $30 \mathrm{LD}$. If, however, $\mathrm{Q}_{\min }=60$, minimum contribution for high-types is $\mathrm{q}_{\min }=20$ and for low-types $\mathrm{q}_{\min }=10$. The payoff for a high-type subject would be $42 \mathrm{LD}$ and for a low-type subject would amount 28 LD.

The game consists of $\mathbf{1 0}$ separate rounds in each of which you will play the same two-stage game remaining the same type. The three other players you will interact with will be the same in every round. In each round you will receive information on suggestions on group minimum contribution levels $\left(\mathrm{Q}_{\min 1}\right.$ to $\mathrm{Q}_{\min 4}$ ), individual contributions ( $\mathrm{q}_{1}$ to $\mathrm{q}_{4}$ ), payoffs (Payoff ${ }_{1}$ to Payoff $_{4}$ ) for all your group members and average levels (D).

If the experiment is complete you will receive the payout of one of the rounds in $€$ (according to the conversion rate stated above). The round to be paid out will be determined randomly. This means you should behave in each round as if it were the round relevant for payout. In the beginning, two trial rounds will be played which are not relevant for payout.

\section{Control questions}

If you have read the instructions and do not have any questions, please answer the following control questions (hint: use the simulator).

1. Please assume that calculating individual minimum contribution levels, $\mathrm{q}_{\min }$, leads to 2 for each of the two low-type players and to 18 for the two high-type players respectively. 
Please indicate the range of your possible contribution levels to the joint project if you are a low-type.

More than and less than or equal

2. Please assume that your contribution as a low-type to the joint project is 10 points. The contributions of the three other group members are 0,10 and 20 . What is your payout?

My payout is

3. Please assume that your contribution as a low-type to the joint project is 0 points. The contribution of the three other group members is 0,10 and 20 . What is your payout?

My payout is

4. Please assume that all three players have contributed 20 points to the project. Which of the following contribution levels results in your highest payout (please check the according box)?
O 0 points
O 5 points
O 10 points
O 20 points

5. Please assume that all three players have contributed 20 points to the project. Which of the following contribution levels results in the highest payout for the group (please check the according box)?
O 0 points
O 5 points
O 10 points
O 20 points

If you have answered all questions, please signal us. We will then check your answers. The game begins when all participants in the experiment have successfully completed the test.

Good luck in the experiment! The MaXLab-Team 
Selected Screenshots for min-I-Q-eq treatment

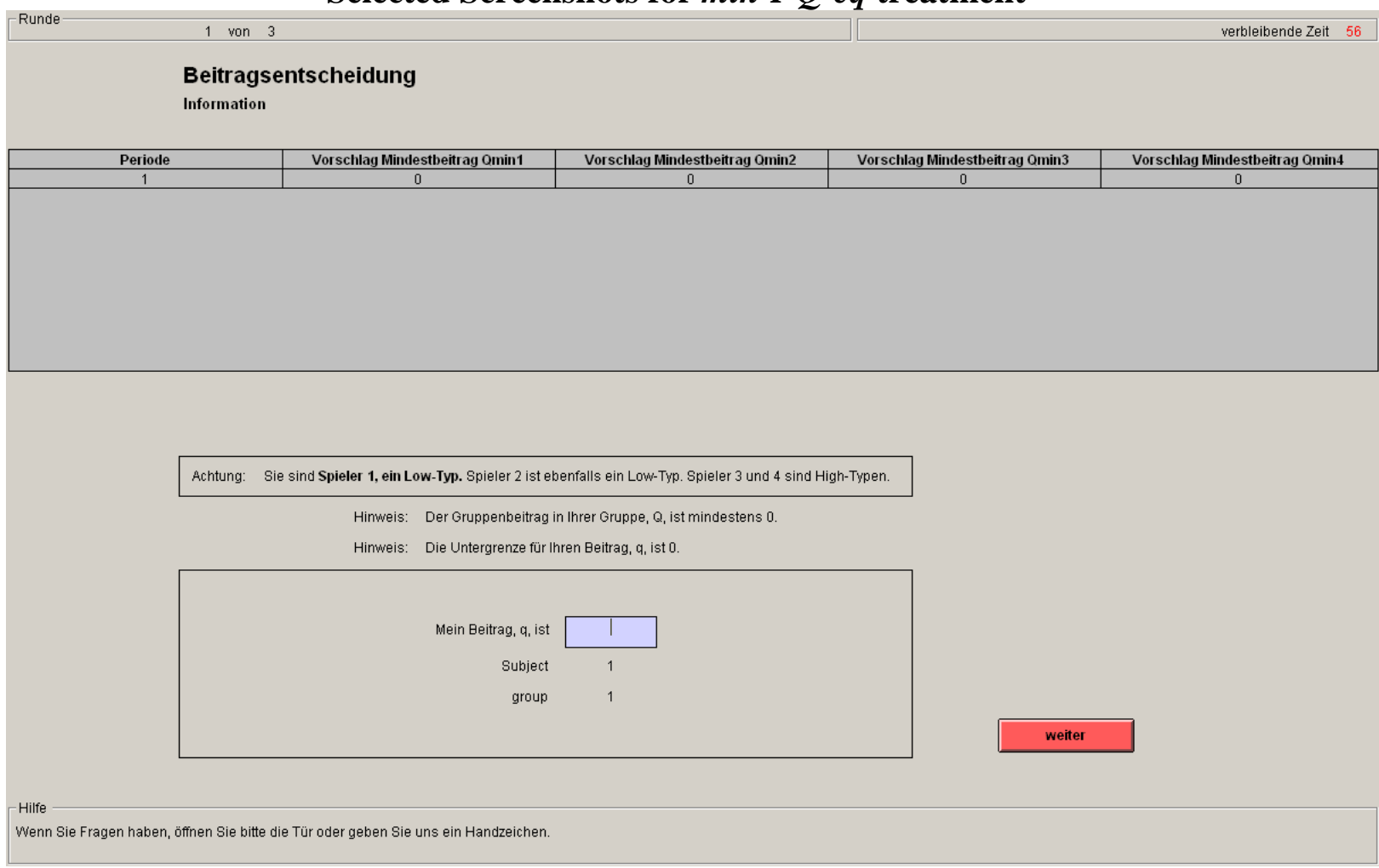

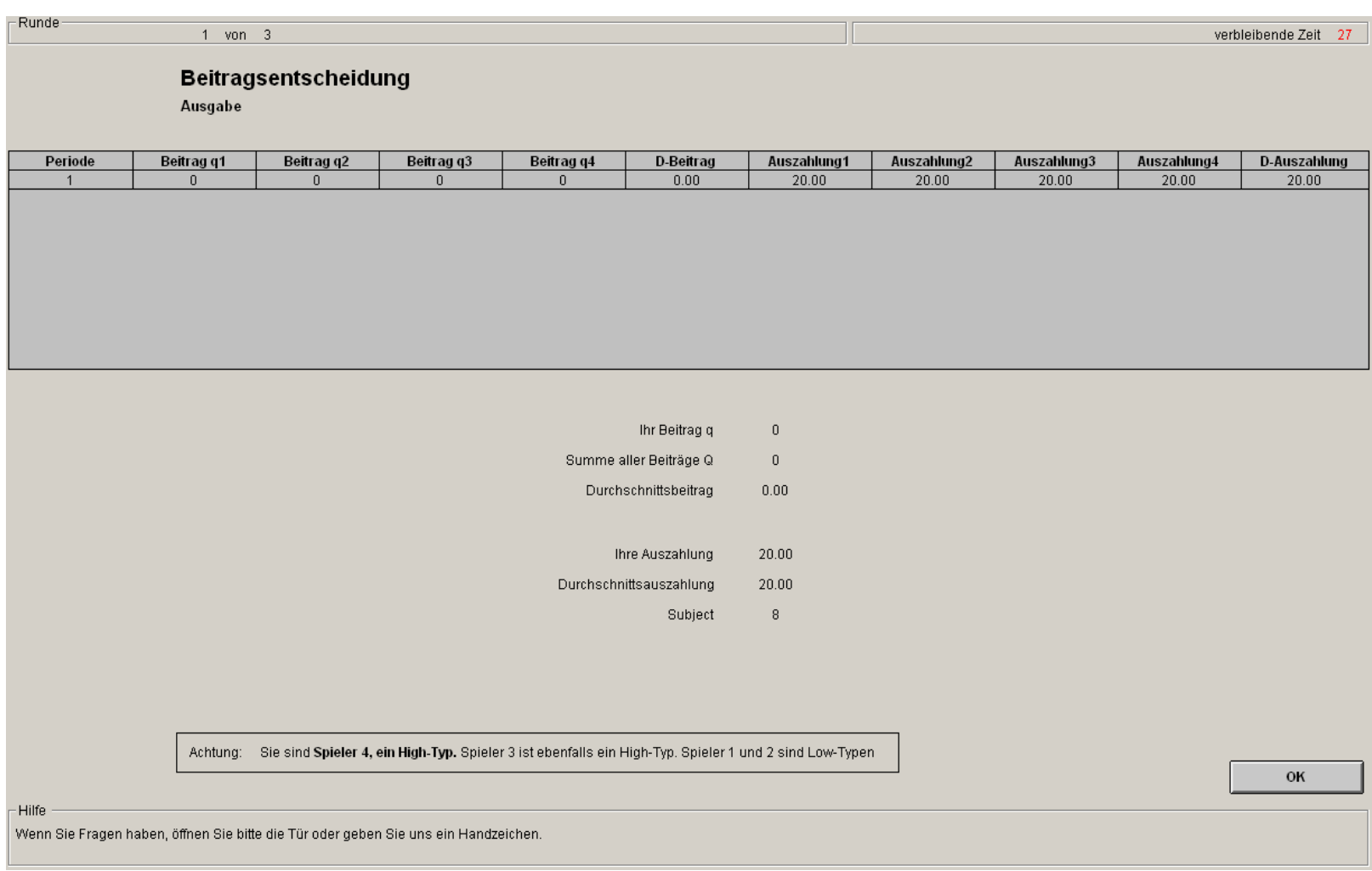

